\title{
SUBARACHNOID PHENOL BLOCK IN THE TREATMENT OF PAIN AND SPASTICITY
}

\author{
By Harvey D. CaIN \\ Kaiser Foundation Rehabilitation Centre, Vallejo, California, U.S.A.
}

In 1955, Maher in England first described the use of subarachnoid injections of phenol solutions in the treatment of intractable pain resulting from cancer ${ }^{1}$. Since then, numerous investigators have confirmed the efficacy of this procedure for treatment of severe pain problems and for relief of spasticity due to various neurologic conditions. ${ }^{2-11}$ Our experience with the first 43 patients whom we have treated with subarachnoid phenol blocks for pain and spasticity is reported in this article.

\section{PROPERTIES OF PHENOL}

Carbolic acid or phenol is a weak acid $(\mathrm{KA}=\mathrm{I} \cdot 7 \times \mathrm{IO}-\mathrm{IO})$ with bactericidal and caustic properties. Phenol is used in various preparations and concentrations as a topical analgesic, antipruritic, disinfectant, or cauterising agent; and is used in injectable form to destroy or attenuate nerve function, and to produce fibrosis about ligaments (prolotherapy). Lipid solutions of phenol dissolved in glycerin or ethyl iodophenylundecylate (Pantopaque) ${ }^{\star}$ are less caustic than aqueous phenol solutions. The effect of 5 per cent. lipid solution upon nerve fibres is approximately the same as an $0 \cdot I$ per cent. aqueous solution. ${ }^{12}$ To cause permanent destruction of all nerve fibres, a 25 per cent. lipid-phenol solution is required. ${ }^{5}$

Animal experiments have shown that there is a differential blocking effect of phenol solutions upon the various action potentials of nerve roots. The function of small nerve fibres - the gamma fibres which mediate spasticity and the ' $C$ ' fibres which mediate pain-is more severely and more permanently impaired by exposure to various concentrations of phenol than are the larger nerve fibres. ${ }^{12,13}$ This differential effect of phenol-relief of pain and spasticity with minimum involvement of voluntary motor activity and sensory perception-is one basis of its unique clinical value. Histologic studies on animals and patients, however, have shown that nerve fibres of all sizes show a similar degree of myelin degeneration following exposure to a phenol solution. Thus, the differential physiologic effect of phenol upon nerve function does not correspond to results of the pathological examination. ${ }^{14,15,16}$ Post-mortem examinations of humans have occasionally shown evidence of arachnoiditis in the area of phenol application, but no clinical systemic or meningitic reactions (as have been noted following subarachnoid alcohol blocks) have been reported.

\section{CLINICAL PROBLEMS AND TREATMENT OF SPASTICITY AND PAIN}

Spasticity and pain are two major problems in the rehabilitation of patients with injury or disease of the central nervous system. Spasticity itself frequently causes pain. Furthermore, muscle spasticity interferes with movement, predis-

* Pantopaque is the Lafayette Pharmaceutical Company trade name for iodophenylundecylate. 
poses to joint contractures, makes bracing of extremities difficult, and causes difficulties with bladder function and catheter care. Involuntary spastic movements also can lead to decubiti and may disturb proper positioning in bed or wheelchair.

The results of various methods of treatment aimed at control of spasticity are often disappointing. Bracing to prevent contractures may increase spasticity and cause pressure sores of the skin. Muscle-relaxant drugs usually are only partially effective for relief of severe spasticity. Nerve blocks, neurectomies, tenotomies, and surgical or chemical procedures to the spinal cord-depending upon location and magnitude of the spasticity-have often been required for relief. Unfortunately, valuable sensory and motor function may be sacrificed by surgical and chemical procedures for relief of diffuse spasticity. However, phenol in glycerin solution is hyperbaric in relation to cerebrospinal fluid and therefore can be placed around the desired nerve roots with a high degree of selectivity.

Persistent severe pain may require nerve blocks and neurosurgical procedures, including cordotomy and lobotomy, for relief and avoidance of the complication of narcotic addition. Subarachnoid alcohol blocks, performed for many years, have the disadvantage of being indiscriminately destructive to all nerve fibres in the area of injection. In adddition, they can cause painful arachnoiditis. Because alcohol is hypobaric with respect to spinal fluid, it cannot be placed selectively except in the grossest sense. The resultant atonic bladder, relaxed rectal sphincter and occasional increased postural hypotension create problems in establishing reliable bowel and bladder programmes. The effectiveness of the relatively simple procedure of subarachnoid phenol block for relief of severe pain was attested to by Marks- 86 of his patients were treated by this procedure and only I 7 subsequently required cordotomy. ${ }^{8}$

\section{PREPARATION OF SOLUTION}

Phenol crystals are weighed according to the concentration desired and are dissolved in $5 \mathrm{ml}$. of anhydrous glycerin. The solution is then sterilised by heating to $160^{\circ} \mathrm{C}$. for one hour. ${ }^{6}$ The concentration of phenol most often used is 5 per cent., although we have used solutions ranging from 2 to is per cent. Experimental evidence regarding the stability of the phenol-glycerin solutions is lacking. Some reports indicate that ampules can be stored for use in the indefinite future, while others state that the potency may deteriorate and recommend a fresh solution for each injection. Although we have found that our phenol solutions stored several months have had the expected clinical effectiveness, we use a freshly prepared solution whenever possible.

Phenol in Pantopaque mixtures $(R)$ have the definite advantage that they can be placed in the subarachnoid space with precision using X-rays for location. However, Pantopaque $(\mathrm{R})$ may produce arachnoiditis and must be removed from the subarachnoid space. Furthermore, comparisons of therapeutic results obtained using equal concentrations of phenol in glycerin and phenol in Pantopaque (R) indicate that the former gives greater reduction in spasticity and a longer period of effectiveness. Liversedge and Maher have attributed this difference in effective action to a slower release of phenol from Pantopaque and to the globular emulsive form of Pantopaque compared to glycerin's direct adherence to the neural roots. ${ }^{7}$ We feel that placement of phenol-glycerin solutions can be controlled accurately by clinical observation and have used this method in all except our first case. 


\section{TECHNIQUE}

Following subarachnoid administration of phenol there is considerable variation in individual responses; therefore, conservative policy usually dictates starting with a weak concentration, particularly when sensation or muscle function is intact. Later injections with stronger solutions can be made if necessary. In the treatment of patients with complete spinal cord lesions ro per cent. phenol in glycerin may be used initially.

Proper positioning of the patient is extremely important. The patient is placed in bed lying on the side to be treated. The spine is curved laterally by raising the head and foot of the bed so that the nerve roots to be treated are at the lowest point. For caudal blocks, the sitting position is utilised since the phenol-glycerin solution is hyperbaric. A motorised bed with pushbutton controls is especially useful for making changes in position easily and rapidly.

A lumbar subarachnoid puncture is performed at the level of the nerve roots to be treated. Warming the phenol in glycerin solution by placing the glass container in a pan of warm water for five minutes will decrease the viscosity and facilitate injection. About one-third of one millilitre of phenol-glycerin solution is injected initially. If sensation is intact, the patient should experience at once a transient feeling of warmth, tingling, or numbness in the dermatomal distribution of the nerve root with which the phenol-glycerin solution has come in contact. At the same time an assistant, standing on the other side of the bed, determines the location of the affected nerve roots by checking repeatedly the patient's perception of pin prick, deep tendon reflexes, anocutaneous reflex, muscle tone and motor function if present. Using the patient's subjective sensations and objective responses, the location of the solution is determined and necessary adjustments made by raising or lowering the foot or head of the bed as indicated. The foot of the bed is raised and the shoulders lowered if involvement of higher nerve roots is desired; the head of the bed is raised and the hips lowered if lower nerve roots are to be affected. Maximal effect from the phenol occurs in the first ten minutes. The remainder of the solution, usually $0.2 \mathrm{ml}$. to $0.3 \mathrm{ml}$. with constant monitoring of the clinical effects. The patient is kept in the finally determined position for 30 minutes after completion of the injection.

If both lower extremities are to be treated, it is preferable that the more involved side be done initially, and the less involved side separately at a later time. However, on several occasions we have left the needle in place in the subarachnoid space and after 30 minutes have turned the patient and done the phenol block on the opposite side. Although we did not have complications with this technique, the reduction in pain and spasticity was usually not as good on the second side as when done separately. Probably this was because we were hesitant to use as much phenol-glycerin solution as would have been injected in a separate procedure.

All of the blocks in this series were to the low thoracic, lumbar, or sacral nerve roots. Other investigators have reportedly had good results in treating pain in the upper thoracic and cervical areas. ${ }^{1,6,8}$ Except when unusually severe spasm, in conjunction with definite evidence of complete spinal cord transection, was present, subarachnoid phenol blocks were not done earlier than six months after injury or onset of symptoms. 
RESULTS

During a I4-month period, 43 patients have been given a total of 86 subarachnoid phenol blocks. The breakdown of the diagnoses of these patients is:

$\begin{array}{lr}\text { Traumatic quadriplegia } & \text { I6 } \\ \text { Traumatic paraplegia } & 7 \\ \text { Hemiplegia due to head injury } & 5 \\ \text { Hemiplegia due to stroke } & 2 \\ \text { Multiple sclerosis } & 8 \\ \text { Cancer } & 5\end{array}$

Since many patients had several blocks and many had problems involving both pain and spasticity, the number of procedure tabulations exceeds the number of patients treated. Therapeutic response concerning both pain and spasticity was graded: excellent (complete), good, fair or no relief. Good relief indicates 50 per cent. or more relief, but less than complete relief. Fair relief indicates some relief but less than 50 per cent relief. This gradation involved a synthesis of the patient's subjective responses and clinical evaluation of objective signs.

\section{TREATMENT OF PAIN}

In the treatment of pain, 33 blocks were performed on I9 patients (tables I and II). Following either a single block or a series of blocks, the end result was fair to good reduction of pain in 16 patients (84 per cent.), and complete and permanent relief in one. Fifteen per cent. of the initial blocks gave no clinical evidence of relief of pain. These initial blocks were generally with weak solutions, and subsequent blocks with stronger solutions were effective.

Case I. V. B. was a 58-year-old bedridden, emaciated woman, with far-advanced breast cancer and bone metastases. She complained of severe pain in both hips and $\mathrm{X}$-rays revealed extensive bone destruction about the pelvis and upper femurs. She required injections of meperidine every two or three hours for pain relief. Sitting up in a chair was not possible and even turning in bed was extremely painful. A subarachnoid block was done on the right side at the LI-2 interspace with $\mathrm{I} \cdot 0 \mathrm{ml}$. of $7 \frac{1}{2}$ per cent. phenol in glycerin with subsequent good relief of pain but moderate weakness of hip flexion and knee extension as well as numbness over the anterior thigh in the distribution of $\mathrm{LI}-2-3$ dermatomes ensued. A second subarachnoid block was done on the left side using $\mathrm{I} \cdot 5 \mathrm{ml}$. of 4 per cent. phenol in glycerin. Again, there was good relief of pain, but no weakness or loss of sensation occurred in the left leg. Subsequently, she was able to move about with much less discomfort and to sit comfortably in a chair. Meperidine was discontinued without difficulty, and she was able to return home. Some sensation gradually returned in the $\mathrm{L}_{3}$ dermatome of the right leg, but the weakness in the hip flexors and knee extensors of the right leg persisted. Since the patient did not have the general strength necessary for walking, this weakness was not a clinical factor. Until her death three months later, pain remained minimal.

\section{TREATMENT OF SKELETAL MUSCLE SPASTICITY}

Sixty-seven subarachnoid phenol blocks were done in 33 patients for treatment of spasticity (table III). Fair to good reduction in spasticity occurred in I 7 patients (5I per cent.) and excellent results were obtained in I 5 patients (45 per cent.). This latter category was comprised of severely paralysed patients with cervical spinal cord injuries in whom solutions stronger than 5 per cent. were frequently used. 


\section{TABLE I}

\begin{tabular}{|c|c|c|c|}
\hline Number & Disease or disorder & Area of pain & $\begin{array}{l}\text { Final degree } \\
\text { of relief }\end{array}$ \\
\hline I & Multiple sclerosis & Legs & Complete \\
\hline 2 & Multiple sclerosis & Legs and bladder & Good \\
\hline 3 & Multiple sclerosis & Legs & None \\
\hline 4 & $\begin{array}{l}\text { Multiple sclerosis } \\
\text { and hip fracture }\end{array}$ & Hip & None \\
\hline 5 & Multiple sclerosis & Legs & Fair \\
\hline 6 & Quadriplegia & Legs & Fair \\
\hline 7 & Quadriplegia & Below waist & None \\
\hline 8 & Quadriplegia & Legs & Fair \\
\hline 9 & Quadriplegia & Legs & Fair \\
\hline IO & Quadriplegia & Legs & Fair \\
\hline I I & Metastatic breast cancer & Hips & Good \\
\hline I2 & Cancer of vagina & Perineum & Good \\
\hline I3 & $\begin{array}{l}\text { Sarcoma, paravertebral, } \\
\text { Tio area }\end{array}$ & Back & Fair \\
\hline I4 & Cancer of rectum & Perineum & Good \\
\hline 15 & Cancer of prostate & Perineum & Good \\
\hline 16 & Paraplegia & Junctional & Fair \\
\hline 17 & Paraplegia & Legs and perineum & Good \\
\hline I8 & Hemiplegia & Leg and hip & Good \\
\hline 19 & Hemiplegia & Leg and hip & Good \\
\hline
\end{tabular}

TABLE II

Treatment of Pain

Degree of

Improvement

None .

Fair .

Good .

Excellent
Patients

No. \%

2 I I

842

842

I 5

I9 100

TABle III

Treatment of Spasticity

Degree of

Improvement

None.

Fair.

Good .

Excellent
Patients

No. \%

I 3

4 I 2

I3 40

I5 45 
Case 2. H. O., a 55-year-old school-teacher, has been retired for seven years following an attack of transverse myelitis which caused his legs to become paralysed and severely spastic. He was confined to his wheelchair but had sufficient motor control to raise his lower extremities off the bed, and to stand while transferring to and from his wheelchair. With assistance from his arms and severe involuntary extensor spasticity in the lower extremities, he was able to ambulate slowly in parallel bars, but with marked scissoring of gait. Involuntary muscle spasticity was quite uncomfortable and disturbing, especially at night. Lower extremity dressing was impossible. Transferring in and out of a car was slow and difficult because of the strong muscle spasms. A continuous, moderately severe feeling of pain and discomfort in both legs and deep in his rectal and perineal areas further added to his discomfort. Appreciation of all sensory modalities was greatly impaired below the $\mathrm{T}_{7}$ level bilaterally. An indwelling Foley catheter and frequent painful bladder spasms were distinctly uncomfortable. The first subarachnoid block was done on the left side using $2 \mathrm{ml}$. of 2 per cent. phenol in glycerin injected at the LI-2 level. The solution was allowed to flow down over all nerve roots below the level of injection so that spasticity was diminished in the hip, knee, and ankle while deep tendon reflexes and the anocutaneous reflex on the left were abolished. Immediate good relief of pain occurred, but there was also some weakness. He could still move all muscle groups, but immediately after the block he could no longer raise his leg off the bed nor bear weight on the leg without using a brace. A second block was done on the right side using $2 \mathrm{ml}$. 2 per cent. phenol in glycerin with the same technique. This produced good relief of pain in the leg and perineal area, although not quite as much as had occurred on the left. Deep tendon reflexes were moderately diminished but motor strength was essentially unchanged. Bladder spasms were abolished and the catheter was no longer uncomfortable. Cystometrograms done before and after the block showed marked decrease in detrusor activity. Some difficulty with constipation lasted for a week after the second block, but then returned to its previous state. Although the anocutaneous reflex was lost, rectal sphincter tone remained good and he was never incontinent. At the time of last examination, I I months after the blocks, both legs remained quite relaxed with only slight return of spasticity and deep tendon reflexes. Plantar stimulation of both feet produced only weak flexor and extensor spasms in the right leg. The patient stated that he no longer had any difficulty with dressing and transferring and that the scissoring in gait had completely disappeared. He indicated that he seldom had any pain in either leg and that the pain in the rectal and perineal area was about one-third the previous intensity. Also, a chronic intertriginous rash around the scrotum and upper thighs cleared completely once the legs could be kept apart.

\section{TREATMENT OF BLADDER SPASTICITY}

Seventeen blocks were done in I3 patients to reduce bladder spasticity, discomfort, autonomic hyperreflexia (with sweating, hypertension, and headache), leaking of urine around the catheter, and recurrent episodes of fever associated with reflux and pyelonephritis. The results were good or excellent in all patients. Decreased detrusor activity and increased bladder capacity was confirmed by cystometrograms and cystograms.

Case 3. J. W., a 36-year-old man, had complete paraplegia following a TI2 spinal cord injury. He had minimal spasticity in both legs, frequently had leaking around his indwelling catheter, and had been hospitalised on numerous occasions for treatment of acute pyelonephritis. Results of a cystometrogram indicated a severely spastic bladder with a capacity of only $50 \mathrm{ml}$. and bilateral ureteral reflux. Penile erections were infrequent and ineffective for intercourse.

With the patient in a sitting position, $\mathrm{I} \cdot 0 \mathrm{ml}$. of 4 per cent. phenol in glycerin was instilled into the subarachnoid space, the anocutaneous reflex was abolished, and bladder 
capacity was expanded to $380 \mathrm{ml}$. The patient had no further urinary problems until three months later when he reported recurrence of leaking around his catheter. Another block was done using 6 per cent. phenol in glycerin. He has had no further difficulty at the time of the last visit five months later. Following this block, penile erections did not occur. No change occurred in his bowel programme, which was well regulated and devoid of incontinence.

\section{COMPLICATIONS OF PHENOL BLOCKS}

I. Increase in Muscle Weakness. Complication of further muscle weakness occurred following 25 per cent. of the 28 blocks done upon patients whose motor function was at least partially intact prior to the blocks. The weakness was generally mild and transient. In four of the six cases with moderate or severe weakness, solutions greater than 5 per cent. were used. No leg weakness developed in the three ambulatory patients who had sacral blocks in the pelvic area for cancer.

2. Sensory Loss. In the $5 \mathrm{I}$ blocks done to patients whose sensation was at least partially intact, a minimal degree of loss occurred in 25 per cent., moderateloss in 2 per cent., and areas of complete loss in 10 per cent. Solutions of $7 \frac{1}{2}$ per cent. or greater were used in all of these cases in which moderate or severe loss occurred.

3. Genitourinary Dysfunction. Inpairment of bladder function is another potential complication of subarachnoid phenol blocks, but there was no loss of bladder control in any of our patients who did not require a catheter prior to the blocks. Loss of penile erections occurred in only one patient and this was anticipated as he required a sacral block for relief of bladder spasticity.

\section{DISCUSSION}

We feel that subarachnoid injection of phenol in glycerin is an extremely valuable therapeutic approach to the problem of control of pain and spasticity in certain selected cases of severe disability, especially of the magnitude often encountered in a rehabilitation centre. However, only if the potential complications of this procedure are carefully considered can the physician and patient decide on the most appropriate method of treatment. Although the actual complications have been minimal, we concur with the statement by Mark et al. ${ }^{8}$, that the indications for subarachnoid injection of phenol should be similar to those used for cordotomy and other major neurosurgical procedures. Patients should always be fully informed, before any procedure is done, of the risks to voluntary motor function and sensation so that they have a comprehensive concept of the problem involved.

In patients with severe spasticity due to permanent complete spinal cord lesions, results following phenol blocks have been the most gratifying. There is, of course, no sensation or motor power to be lost, and with painstaking placement of the solution, interference with bladder contractions, erections, and rectal sphincter tone can be kept to a minimum. Whereas some difficulty was encountered with patient acceptance of subarachnoid alcohol blocks because of destruction of the lower sacral nerves with loss of rectal sphincter tone and penile erections, this has not been an uncommon problem with subarachnoid phenol blocks. Frequently the patient initiates the discussion of a possible phenol block after talking with other patients who have had the procedure done.

The ability of a paraplegic patient to dress himself and to transfer in and out of his wheelchair is greatly enhanced when spasticity is relieved. This has been the 
case whether the patient's voluntary motor function is unchanged, weakened, or increased following the block. Our composite experience has been that voluntary motor function is frequently better following the block because reduction of spasticity unmasks previously occult muscular potentials.

We are now using $7 \frac{1}{2}$ to Io per cent. in glycerin solutions for the initial injection in patients with complete cord lesions. It should be stressed, however, that very careful consideration must be given to the patient with an incomplete spinal cord lesion who has some appreciation of sensation or motor control in his lower extremities. If there is a specific area of difficulty such as a scissoring gait due to spastic hip adductors, it may be attacked locally by tenotomy, neurectomy, or peripheral nerve injection. One hemiplegic patient in this category in our series had good relaxation of his adductors following a block to the LI-2 area on the affected side; and walked much better following the procedure. In contrast, a second patient with a similar problem developed enough weakness of the knee extensors on the injected side so that a long leg brace was required for ambulation. However, when the problem of pain or spasticity is diffuse and would require multiple major procedures, the problem should be discussed in detail with the patient outlining the potentials of loss of movement and sensation.

In order to evaluate the effect in patients with partial spinal cord lesions we often use initial weak solutions of 2 to 3 per cent. phenol in glycerin. Complications following use of these weak concentrations are usually transient and the patient and physician can decide on the basis of the results whether a stronger block is indicated. In many cases, patients have decided that even though there was some loss of sensation and motor power, the results in relieving the spasticity or pain more than offset this loss. Phenol-glycerin blocks are most frequently done for spasticity about the hip and knee; therefore, any loss of sensation is usually confined to the anterior aspect of the thigh. This is of little consequence since sensation is not affected over the buttocks, feet, or genital areas.

In management of some problems of severe pain, we find it helpful to first perform a diagnostic spinal anaesthetic block with an agent of transient effect, such as lidocaine. We are thereby able to ascertain whether or not the pain is of central or peripheral origin and to determine whether or not use of phenol will be beneficial.

A major factor in favour of phenol in glycerin blocks is the relative simplicity of the procedure. On several occasions we have performed the blocks in an outpatient setting, avoiding the need for hospital admission and additional expense.

At each point in the use of this procedure, we try to educate the patient about the causes of the pain and spasticity, the nature of various therapeutic techniques and to give the patient ample time to make his own decisions. An informed consent from the patient is an essential prerequisite for this procedure.

\section{SUMMARY}

We feel that in the management of moderate to severe pain or spasticity the subarachnoid phenol block is an effective and relatively simple therapeutic technique. The frequency of complications, though usually mild and transient, is closely associated with the concentration of phenol used. Performance of a series of phenol blocks, beginning with weak phenol concentrations, will permit the physician to titrate to the desired effect with a minimum of side-effects and complications. 
Patients are selected on the basis of severity of signs and symptoms, and failure to respond to more conservative measures.

\section{RÉSUMÉ}

Nous pensons que, dans le traitement de douleurs, modérées ou sévères, ou spacticité, l'injection intra-rachidienne de Phénol est un moyen effectif et de technique simple. La fréquence des complications, d'habitude modérées et transitoires, dépend de la concentration utilisée. La pratique d'une série d'injections, commençant avec une concentration faible, permettra au médecin d'obtenir les résultats voulus avec le minimum d'effets désagréables et de complications.

Les malades sont choisis en rapport avec la sévérité des signes et symptômes, et de l'échec du traitement conservateur.

\section{ZUSAMMENFASSUNG}

Wir sehen in dem subarachnoidalen Phenolblock eine wirksame und verhältnismässig einfache Methode zur Behandlung mässiger oder starker Schmerzen oder Spastizität. Komplikationen sind im allgemeinen leicht, vorübergehend und stehen in direktem Verhältnis zu der Stärke der Phenollösung. Wenn der Arzt eine Serie solcher Blockierungen mit graduell steigender Konzentration des Phenols vornimmt, kann er den erwünschten Erfolg mit einem Minimum von Komplikationen ereichen. Patienten wurden der Phenolbehandlung unterworfen, wenn ihre Symptome schwer genug waren und auf weniger drastische Behandlung nicht reagiert hatten.

\section{REFERENCES}

I. MAHER, R. M. (1955). Relief of pain in incurable cancer. Lancet, I, I8-20.

2. MAHER, R. M. (I957). Neurone selection in relief of pain: further experience with intrathecal injections. Lancet, I, I6-I9.

3. Nathan, P. W. \& ScotT, T. G. (I958). Intrathecal phenol for intractable pain: safety and dangers of method. Lancet, $\mathbf{I}, 76-80$,

4. Kelly, R. E. \& Gautier-Smith, P. C. (1959). Intrathecal phenol in the treatment of reflex spasms and spasticity. Lancet, 2, I IO2-I I05.

5. Nathan, P. W. (1959). Intrathecal phenol to relieve spasticity in paraplegia. Lancet, 2, IO99-I IO2.

6. Brown, A. S. (I958). Treatment of intractable pain by subarachnoid injection of carbolic acid. Lancet, 2, 975-978.

7. Liversedge, L. A. \& MAHER, R. M. (1960). Use of phenol in relief of spasticity. Brit. med. F. 2, 3I-33.

8. Mark, V. H., White, J. C., Zervas, N. T., Ervin, F. R. \& Richardson, E. P. (I962). Intrathecal use of phenol for the relief of chronic severe pain. New Engl. F. Med. 267, 589-593.

9. Lourie, H. \& Vanasupa, P. (1963). Comments on the use of intraspinal phenolpantopaque for relief of pain and spasticity. F. Neruosurg. 20, 60-63.

IO. GoRdON, R. A. \& GoEL, S. (I963). Intrathecal phenol block in treatment of intractable pain of malignant disease. Canad. Anes Soc. F. 1o, 357-363.

i i. Pedersen, E. \& Juul-Jensen, P. (1962). Intrathecal phenol in the treatment of spasticity. Acta Neurol scand. 38, 69-77.

I2. Nathan, P. W. \& Sears, T. A. (I960). Effect of phenol on nervous conduction. F. Physiol. 150, 565-580.

I3. IgGo, A. \& WALSH, E. G. (I960). Selective block of small fibres in the spinal roots by phenol. Brain, 83, 70I-708.

I4. Stewart, W. A. \& Lourie, H. (I963). An experimental evaluation of the effects of subarachnoid injection of phenol-pantopaque in cats: a histological study. $\mathcal{f}$. Neurosurg. 20, 64-72.

I5. Berry, K. \& OlszeWski, J. (1963). Pathology of intrathecal phenol injection in man. Neurol. 13, I52-I 54.

I6. BAXTeR, D. W. \& SCHAChleR, U. (I962). Experimental studies on the morphological changes produced by intrathecal phenol. Canad. med. Ass. F. 86, I200. 